\title{
The efficacy of liposomal bupivacaine compared with traditional peri-articular injection for pain control following total knee arthroplasty: an updated meta- analysis of randomized controlled trials
}

\author{
Yuan Liu, Yi Zeng, Junfeng Zeng, Mingyang Li, Wenxing Wei and Bin Shen ${ }^{*}$ (i)
}

\begin{abstract}
Background: The efficacy of postoperative pain management is an important factor that influences the final outcome of total knee arthroplasty (TKA). Whether liposomal bupivacaine offers better efficacy compared with traditional peri-articular injection after TKA remains inconclusive. We conduct this study to compare the true efficacy of liposomal bupivacaine (LB) with traditional peri-articular injection (TPAl) following TKA.

Materials and methods: Randomized controlled trials (RCTs) from PubMed, EMBASE, and the Cochrane Central Register of Controlled Trials (CENTRAL) and Web of Science were searched. Thirteen RCTs involving 1373 patients were finally included in our meta-analysis $(\angle B=691, T P A I=682)$. The continuous and dichotomous outcome were collected in a standard form, and the data were analysed by using Review Manager 5.3 software. Finally, the results were presented in the forest plots.

Result: The pooled data demonstrated that the postoperative visual analogue score (VAS) in the LB group was not significantly different compared with that in the TPAI group at every time period after TKA. The liposomal bupivacaine group had significantly lower consumption of morphine equivalents 24 to $72 \mathrm{~h}$ postoperatively and reduced incidence of nausea and vomiting after TKA compared with the TPAI group. Finally, the length of hospital stay in the two groups was not significantly different.

Conclusion: Liposomal bupivacaine did not yield different results on the visual analogue scale compared with traditional peri-articular injection after total knee arthroplasty. However, liposomal bupivacaine was preferred in terms of lower consumption of morphine equivalents $24-72 \mathrm{~h}$ postoperatively and lower incidence of nausea and vomiting after total knee arthroplasty.
\end{abstract}

Keywords: Total knee arthroplasty, Liposomal bupivacaine, Traditional peri-articular injection, Pain control, Randomized controlled trial, Meta-analysis

\footnotetext{
* Correspondence: shenbin_1971@163.com

Department of Orthopedics, West China Hospital, West China Medical

School, Sichuan University, 37\# Guoxue Road, Chengdu 610041, Sichuan

Province, People's Republic of China
}

(c) The Author(s). 2019 Open Access This article is distributed under the terms of the Creative Commons Attribution 4.0 International License (http://creativecommons.org/licenses/by/4.0/), which permits unrestricted use, distribution, and reproduction in any medium, provided you give appropriate credit to the original author(s) and the source, provide a link to the Creative Commons license, and indicate if changes were made. The Creative Commons Public Domain Dedication waiver (http://creativecommons.org/publicdomain/zero/1.0/) applies to the data made available in this article, unless otherwise stated. 


\section{Introduction}

As the most effective treatment for advanced osteoarthritis, more than half of patients receive benefits from total knee arthroplasty (TKA), such as alleviation the pain, functional recovery of the knee joint and improvement of the quality of life. However, a limitation that cannot be ignored is that most patients still experience postoperative pain at different levels $[1,2]$. Both surgeons and patients are very worried about this pain. On the one hand, inadequate pain control impedes physical exercise after TKA and increases the demand of rescued opioids. The former could influence the functional recovery and delay early rehabilitation, and the latter could be associated with more adverse effects, such as vomiting, nausea, dizziness, constipation, urinary retention and even respiratory depression $[3,4]$. On the other hand, the efficacy of postoperative pain control could influence the patients' satisfaction for the TKA procedure, and some patients do not undergo TKA due to unaccepted postoperative pain [5]. As a result, many types of postoperative pain control methods have been developed and applied.

Liposomal bupivacaine (LB; EXPAREL ${ }^{\circ}$, bupivacaine liposome injectable suspension; Pacira Pharmaceuticals, Inc., Parsippany, NJ) has a significant advantage of prolonging the effective time of bupivacaine to $72 \mathrm{~h}$ [6]. With the approval of the Food and Drug Administration (FDA) in 2103, liposomal bupivacaine has been safely and effectively applied to surgeries, including TKA, augmentation and mammaplasty, mastectomy with tissue expander placement [7]. To explore the efficacy of liposomal bupivacaine after total knee arthroplasty, a number of clinical trials have been performed to compare the LB with other methods, including peripheral nerve block and, traditional peri-articular injection (TPAI). TPAI is the best candidate to compare with liposomal bupivacaine in terms of minimal confounding bias [8] given that, liposomal bupivacaine was injected into the surroundings of the surgical site to control pain, which is consistent with TPAI.

According to our search results, 4 meta-analyses, 13 randomized controlled trials (RCTs), and 11 non-RCTs comparing liposomal bupivacaine with traditional periarticular injection after TKA were identified. However, meta-analysis outcomes still need to be improved. Wang et al. [9] performed a meta-analysis with 3 RCTs and 2 non-RCTs comparing the LB with bupivacaine after TKA, but the control groups were mixed with local injection and the femoral nerve block, which could produce confounding bias. Kuang et al. [10] conduct a meta-analysis with 4 RCTs and 7 non-RCTs comparing the LB with traditional peri-articular injection after TKA, but the number of RCTs are limited. Sun et al. [11] perform a meta-analysis with 9 RCTs and 7 nonRCTs comparing the LB with traditional peri-articular injection after TKA. The inclusion of non-RCTs is unnecessary when the number of RCTs is sufficient. Therefore, we included 13 RCTs to perform an updated metaanalysis to obtain more believable outcomes to help clinical surgeons make a decision.

\section{Materials and methods}

This meta-analysis was completed in accordance with the Preferred Reporting Items for Systematic Reviews and Meta-Analyses (PRISMA) guidelines for meta-analysis.

\section{Searching}

Liposomal bupivacaine relevant studies from several electronic databases, including PubMed (1966 to Dec 2018), EMBASE (1980 to Dec 2018), and the Cochrane Central Register of Controlled Trials (CENTRAL, Dec 2018) and Web of Science (1966 to Dec 2018) were systematically searched by two reviewers. "Total knee arthroplasty OR replacement" and, "liposomal bupivacaine OR exparel" were used as search key words in connection with AND or OR. There was no limitation on language and locality.

\section{Inclusion criteria}

Studies were selected if they met the following criteria in PICOS order: (1) Population: patients experiencing TKA who were demographically alike; (2) Intervention: periarticular injection of liposomal bupivacaine; (3) Control intervention: traditional peri-articular injection including bupivacaine and cocktail (ropivacaine, epinephrine, ketorolac, clonidine, etc.); (4) Outcomes: postoperative pain score, morphine consumption, adverse effects and the length of stay; (5) Study design: randomized controlled trial (RCT).

\section{Data screening}

Two reviewers independently screened the information listed in a standard form designed to screen the correlative data from included studies. The data extracted included authors, the year of publication, sample capacity, demographical information (age, gender, and body mass index), anaesthetic methods, the composition of agents by peri-articular injection in the experimental and control groups, follow-up, and power analysis. In particular, when we found two studies $[12,13]$ that reported the outcome by the box plot, we obtained the relevant literature and used the scientific method to obtain the mean and variance [14]. Any disagreements were unified through discussion. The primary outcome was postoperative VAS. Secondary outcomes included the consumption of morphine equivalents, the incidence of adverse effects such as nausea and vomiting (NAVO), and length of hospital stay (LOS). 


\section{Risk of bias assessment}

On the basis of the Cochrane Handbook for Systematic Reviews of Interventions 5.0, two reviewers respectively evaluate the methodological quality of included studies. We evaluated the RCTs using the "Cochrane collaboration's tool for assessing the risk of bias," which included the following key points: random sequence generation (selection bias); allocation concealment (selection bias); blinding of participants and personnel (performance bias); blinding of outcome assessment; incomplete outcome data (attrition bias); selective reporting (reporting bias); and other bias. A unified consensus was obtained if there were any different opinions.

\section{Evidence assessment with GRADE approach}

The evidence assessment was determined using the guidelines of the grading of recommendations, assessment, development, and evaluation (GRADE) working group $[15,16]$. The GRADE system uses a sequential assessment of the evidence quality and the evidence grades are divided into the following levels: (1) high, which indicates that further research is unlikely to alter confidence in the effect estimate; (2) moderate, which indicates that further research is likely to significantly alter confidence in the effect estimate and may change the estimate; (3) low, which indicates that further research is likely to significantly alter confidence in the effect estimate and to change the estimate; and (4) very low, which indicates that any effect estimate is uncertain. Uniformity of the estimated effects across studies and the extent to which the patients, interventions, and outcome measures are similar to those of interest may reduce or increase the evidence grade. As recommended by the GRADE working group, the lowest evidence quality for any of the outcomes was used to rate the overall evidence quality. The evidence quality was graded using GRADEpro online software (https://gradepro.org/).

\section{Statistical analysis}

We used Review Manager 5.3 software to analyse pooled data. The effect value of mean differences (MDs) was used to weigh the effect size for continuous outcome.

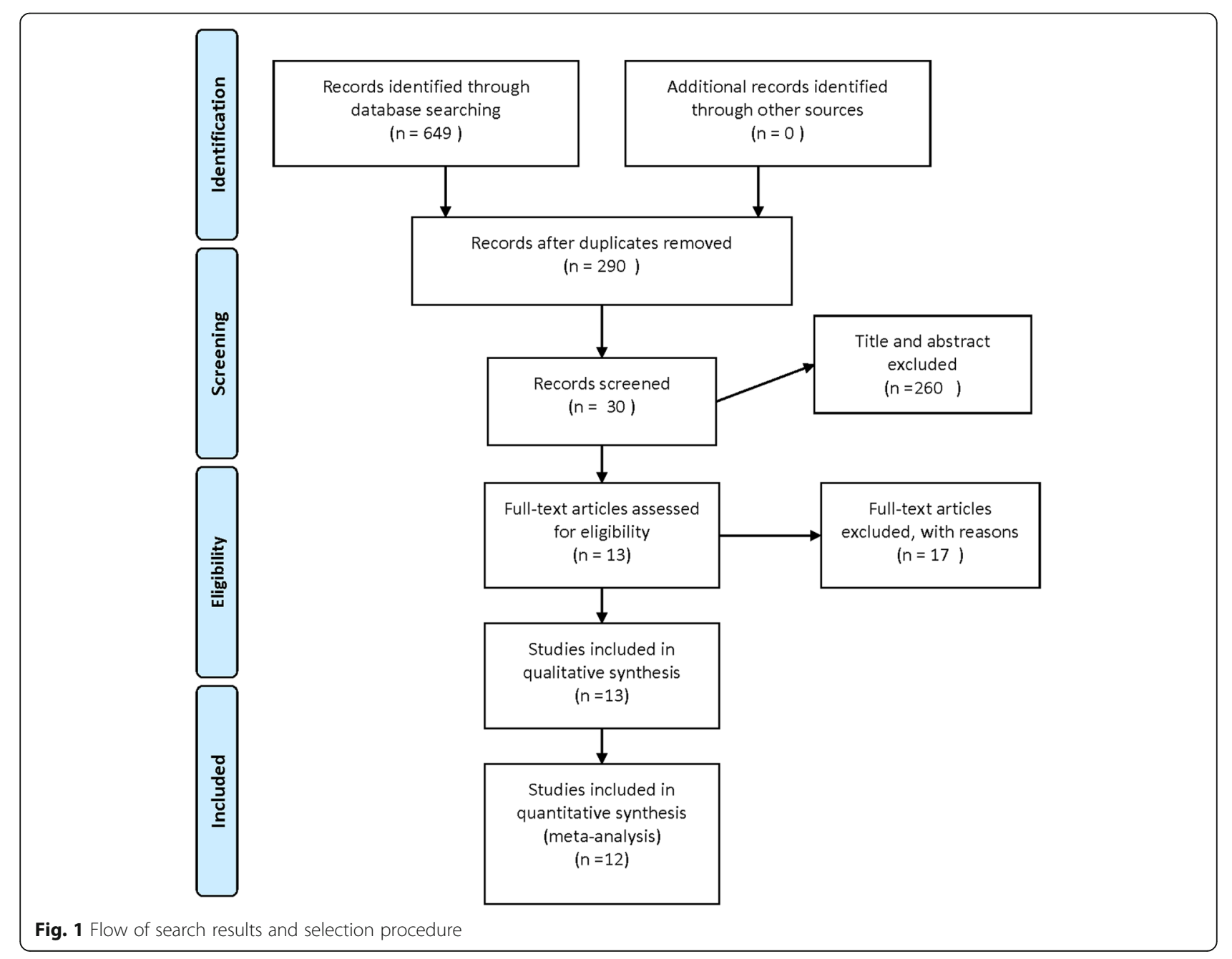


The effect value of relative risks (RRs) was used to measure the effect size for dichotomous outcome. We considered the result to be significantly different when a two-sided $p$-value $<0.05$. We use the $\mathrm{I}^{2}$ statistic to test heterogeneity across the studies. We regarded a $p$-value $\leq 0.1$ or an $\mathrm{I}^{2}>50 \%$ as proof of heterogeneity. A random-effects model was used to eliminate the effect caused by high heterogeneity, and a fixed-effects model was adopted when the heterogeneity lacked statistical evidence. We performed subgroup analysis for postoperative VAS based on the cocktail and standard bupivacaine group to reduce the risk of bias.

\section{Results}

\section{Search result}

A total of six-hundred-forty-nine relevant articles from electronic databases were identified depending on the search strategy. Three-hundred-fifty-nine duplicates were removed. Two-hundred-sixty studies were excluded after reading the abstract. After reading the full text, only nineteen studies comparing liposomal bupivacaine with traditional peri-articular injection were selected. Finally, according to the inclusion criteria for RCTs, 13 RCTs [12, 13, 17-27] with 1373 patients comparing liposomal bupivacaine with traditional peri-articular injection were included. (Fig. 1).

\section{Studies characteristics}

Among of 13 RCTs, seven RCTs [13,17-18,22- 24,27] used bupivacaine as the control group, and the other six RCTs used the cocktail as the control group. The baseline characteristics of each study are presented in Table 1 . All of 13 RCTs are published in the USA. Five [13, 19, 24, 25, 27] of 13 RCTs did not perform power analysis to estimate the sample size needed to acquire significant results. The length of follow-up varied from 0 to 8 weeks.

\section{Risk of bias assessment}

Methodological quality of $13 \mathrm{RCTs}$ was evaluated with Cochrane collaboration's tool for assessing the risk of bias [28]. Randomization was achieved using a random number table in 3 RCTs $[13,25,26]$, excel software in 2 RCTs $[17,20]$, and a centralized randomization system in 2 RCTs $[18,22]$. Only 2 RCTs $[17,19]$ described the concealment of allocation. Only 2 RCTs $[24,26]$ were single blinded, and the others were double-blinded. All RCTs mention information about withdrawal and dropout. The methodological quality of included studies was presented in Fig. 2. Judgements about each risk of bias item are presented as percentages across all included studies in Fig. 3.

\section{Primary outcome: the postoperative pain score}

To decrease the bias caused by two different types of techniques in the control group, we divided the data into

Table 1 The basic information of RCTs

\begin{tabular}{|c|c|c|c|c|c|c|c|c|c|c|}
\hline \multirow[b]{2}{*}{ studies } & \multirow[b]{2}{*}{ country } & \multicolumn{4}{|c|}{$\underline{\mathrm{LB} / \text { traditional PAI }}$} & \multirow[b]{2}{*}{ AN } & \multirow[b]{2}{*}{ EG } & \multirow[b]{2}{*}{ control group } & \multirow[b]{2}{*}{ follow-up } & \multirow[b]{2}{*}{ PA } \\
\hline & & cases & age & female & $\mathrm{BMI}$ & & & & & \\
\hline alijanipour 2016 & USA & $59 / 59$ & $64.3 / 64.9$ & $30 / 32$ & $32.3 / 28.7$ & SA & LB266mg & bupivacaine & 6 weeks & Y \\
\hline Bramlett 2012 & USA & $25 / 34$ & $61.1 / 62.2$ & $12.0 / 23$ & $31.2 / 31.5$ & GA & LB266mg & bupivacaine & 36 days & Y \\
\hline collis 2016 & USA & $54 / 51$ & $63.7 / 63.5$ & $29 / 37$ & $34.1 / 35.7$ & GA & LB266mg & $\begin{array}{l}\text { ropivacaine, epinephrine, } \\
\text { ketorolac, clonidine }\end{array}$ & 8 weeks & N \\
\hline declaire 2017 & USA & $47 / 49$ & $69.7 / 67.7$ & $26 / 28$ & $31.5 / 31.9$ & $\mathrm{SA} / \mathrm{GA}$ & LB266mg & $\begin{array}{l}\text { ropivacaine, ketorolac, } \\
\text { morphine, epinephrine }\end{array}$ & NM & Y \\
\hline Jain 2016 & USA & $63 / 62$ & $68.3 / 67.5$ & $44 / 45$ & $33.3 / 33.3$ & SA & LB266mg & $\begin{array}{l}\text { bupivacaine, epinephrine, } \\
\text { morphine }\end{array}$ & NM & Y \\
\hline mont 2017 & USA & $70 / 69$ & $66 / 66$ & $43 / 39$ & $32.4 / 31.3$ & SA & LB266mg & bupivacaine & NM & Y \\
\hline schroer 2015 & USA & $58 / 53$ & $67 / 68.6$ & $34 / 32$ & $32 / 32$ & SA/GA & LB266mg & bupivacaine & 3 weeks & Y \\
\hline Schumer 2018 & USA & $66 / 64$ & NM & NM & NM & SA & LB266mg & bupivacaine & 6 weeks & $\mathrm{N}$ \\
\hline schwarzkopf 2016 & USA & 20/18 & $63 / 59$ & $13 / 8.0$ & 29.3/29.5 & SA & LB266mg & $\begin{array}{l}\text { ropivacaine, clonidine, } \\
\text { Toradol, Epinepherine }\end{array}$ & NM & Y \\
\hline smith 2017 & USA & $104 / 96$ & $66 / 66$ & $50 / 68$ & $31.5 / 31.6$ & SA & LB266mg & bupivacaine & 6 weeks & $N$ \\
\hline Snyder 2016 & USA & $35 / 35$ & $67.3 / 65.6$ & $13 / 20$ & $30.68 / 31.29$ & $\mathrm{SA} / \mathrm{GA}$ & LB266mg & $\begin{array}{l}\text { ropivacaine,epinephrine } \\
\text { morphine, ketorolac }\end{array}$ & 10 days & $N$ \\
\hline suarez 2018 & USA & $52 / 52$ & $68.1 / 67.3$ & $33 / 26$ & $30.8 / 32.01$ & SA & LB266mg & $\begin{array}{l}\text { bupivacaine,lidocaine } \\
\text { epinephrine, morphine, } \\
\text { ketorolac }\end{array}$ & 6 weeks & Y \\
\hline zlotnicki 2018 & USA & $38 / 40$ & $63.2 / 64.3$ & $19 / 26$ & $35.5 / 35.4$ & $\mathrm{SA} / \mathrm{GA}$ & LB266mg & bupivacaine & NM & $\mathrm{N}$ \\
\hline
\end{tabular}




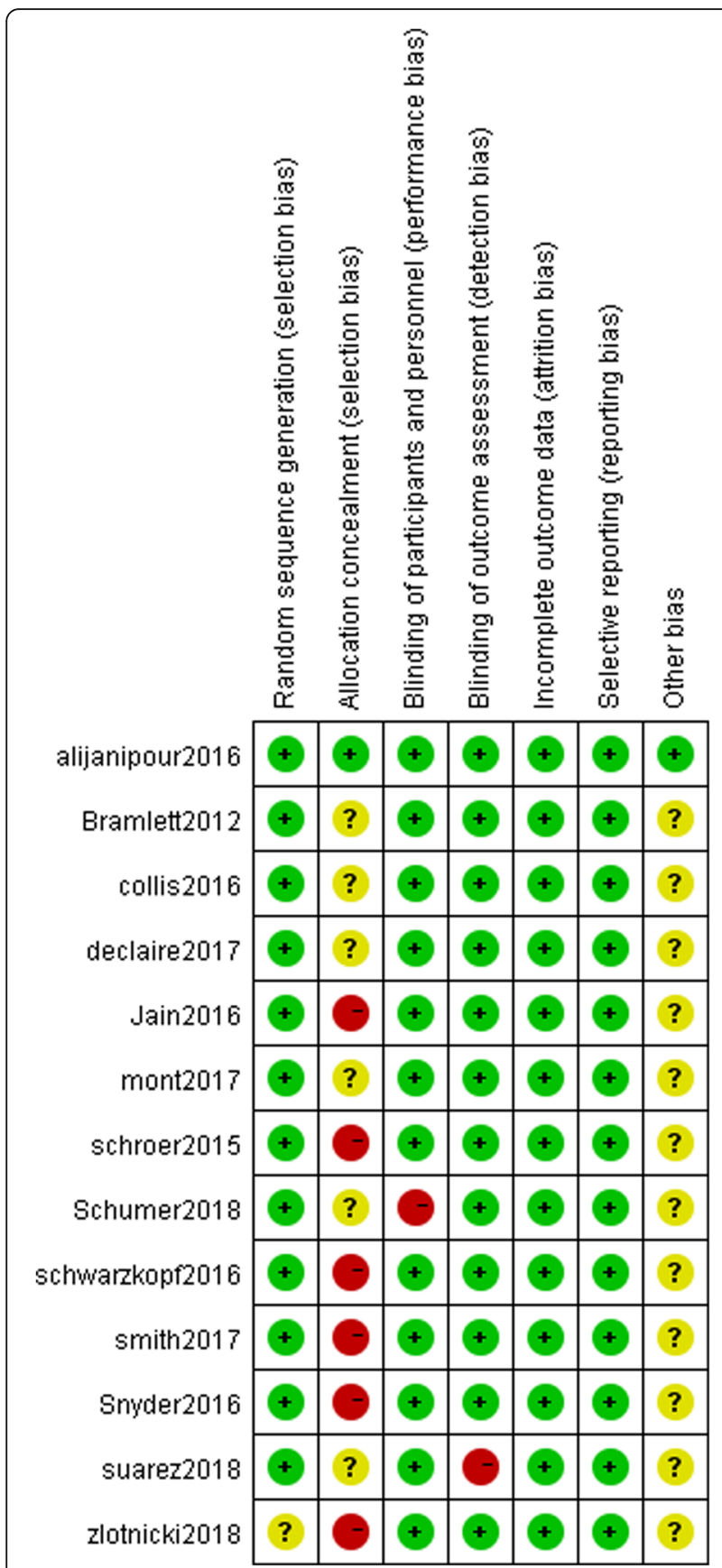

Fig. 2 Methodological quality of included studies

the bupivacaine and cocktail groups to perform a subgroup analysis regarding this outcome.

\section{VAS during the first 24-h period after TKA}

Eight studies involving 765 patients reported the VAS from 0 to 24 h postoperatively [12, 13, 18, 19, 23, 25-27]. The result showed that LB was not significantly different from TPAI regarding VAS during the first 24-h period after TKA $(\mathrm{MD}=0.06,95 \% \mathrm{CI}:[-0.01,0.13], P=0.09$, $\mathrm{I}^{2}=47 \%$, Fig. 4). Fixed-effects meta-analysis revealed that the pain score in the liposomal bupivacaine group is not significantly lower than bupivacaine group $(\mathrm{MD}=-0.33$, 95\% CI: [- $0.85,0.19], P=0.21, \mathrm{I}^{2}=52 \%$, Fig. 4 ), and not significantly higher than the cocktail group $(\mathrm{MD}=0.77$, $95 \%$ CI: $[-0.00,0.14], P=0.06, \mathrm{I}^{2}=35 \%$, Fig. 4 ).

\section{VAS during the second 24-h period after TKA}

Eight studies involving 765 patients described the VAS from 24 to 48 h postoperatively [12, 13, 18, 19, 23, 25-27]. The result showed that LB was not significantly different from TPAI regarding VAS during the second 24-h period after TKA (MD $=0.04,95 \%$ CI: $[-0.01,0.10], P=0.12$, $\mathrm{I}^{2}=51 \%$, Fig. 5). Fixed-effects meta-analysis revealed that the pain score in the liposomal bupivacaine group is not significantly increased compared with the bupivacaine group $\left(\mathrm{MD}=-0.06,95 \% \mathrm{CI}\right.$ : [-0.40, 0.53], $P=0.79, \mathrm{I}^{2}=$ $58 \%$, Fig. 5), and not significantly increased compared with the cocktail group $(\mathrm{MD}=0.04,95 \% \mathrm{CI}:[-0.01,0.10], P=$ $0.13, \mathrm{I}^{2}=58 \%$, Fig. 5).

\section{VAS during the third 24-h period after TKA}

Six studies involving 570 patients recorded the VAS from 48 to $72 \mathrm{~h}$ postoperatively [12, 13, 18, 19, 23, 25]. The result showed that LB was not significantly different from TPAI regarding VAS during the third 24-h period after TKA $\left(\mathrm{MD}=0.05,95 \%\right.$ CI: $[-0.01,0.12], \mathrm{P}=0.12, \mathrm{I}^{2}=64 \%$, Fig. 6) . Fixed-effects meta-analysis revealed that the pain score in the liposomal bupivacaine group is not significantly reduced compared with the bupivacaine group ( $\mathrm{MD}=-0.22,95 \% \mathrm{CI}$ : $[-0.67,0.24], P=0.35, \mathrm{I}^{2}=0 \%$, Fig. 6 ), and not significantly increased compared with the cocktail group ( $\mathrm{MD}=0.06$, 95\% CI: [- 0.01, 0.13], $P=0.08, \mathrm{I}^{2}=82 \%$, Fig. 6).

\section{Secondary outcome}

The consumption of morphine equivalents during hospital stay

Four studies involving 337 patients reported the consumption of morphine equivalents from 0 to $72 \mathrm{~h}$ postoperatively [12, 21, 25, 26]. During the first $24 \mathrm{~h}$, fixed-effects meta-analysis revealed that patients in the liposomal bupivacaine group did not consume significantly less morphine equivalents than TPAI (MD $=-1.22,95 \% \mathrm{CI}$ : [-4.37, 1.94], $P=0.45, \mathrm{I}^{2}=40 \%$, Fig. 7). During the second $24-\mathrm{h}$ period, fixed-effects meta-analysis revealed that patients in the liposomal bupivacaine group consumed significantly less morphine equivalents than TPAI ( $\mathrm{MD}=-5.31,95 \%$ CI: $[-9.46,-1.17], P=0.01, \mathrm{I}^{2}=0 \%$, Fig. 7). During the third 24-h period, fixed-effects meta-analysis revealed that patients in the liposomal bupivacaine group consumed significantly less morphine equivalents than TPAI $(\mathrm{MD}=-$ 6.64, 95\% CI: [-11.40, -1.88$], P=0.006, \mathrm{I}^{2}=38 \%$, Fig. 7). 


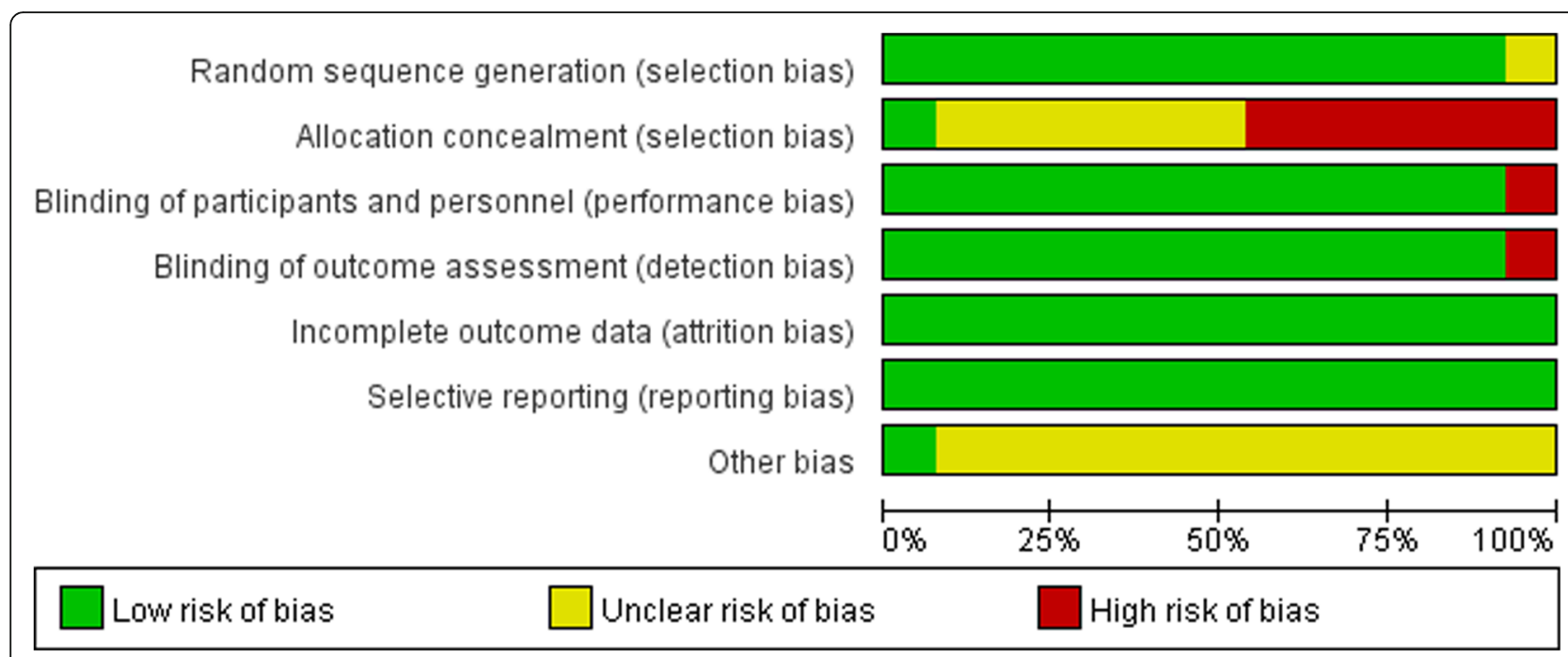

Fig. 3 Risk of bias assessment of included studies

\section{The incidence of postoperative nausea and vomiting}

Five studies involving 509 patients described the incidence of postoperative nausea and vomiting (NAVO) [18, 22-25]. Fixed-effects meta-analysis revealed that the incidence of NAVO in the liposomal bupivacaine group is reduced compared with the control group $(\mathrm{RR}=0.78,95 \% \mathrm{CI}$ : [0.61, 1.01], $P=0.05, \mathrm{I}^{2}=62 \%$, Fig. 8) A significant difference might be obtained from a larger sample size.

\section{The length of hospital stay}

Seven studies involving 871 patients recorded the length of hospital stay [13, 19-21, 23, 24, 26]. Fixed-effects meta-analysis revealed that the length of hospital stay in the liposomal bupivacaine group is not significantly longer compared with the control group $(\mathrm{MD}=0.04,95 \%$ CI: $[-0.07,0.15], P=0.50, \mathrm{I}^{2}=25 \%$, Fig. 9).

\section{Quality of the evidence in the GRADE system}

As shown in Table 2, a total of eleven outcomes in this meta-analysis were evaluated using the GRADE system (Table 2). The quality of evidence in the following two outcomes was high: VAS $(0-24 \mathrm{~h})$ cocktail and, length of stay. The outcome VAS (48-72 h) cocktail had a low quality of evidence. The remaining eight outcomes had moderate quality of evidence. Therefore, we believed

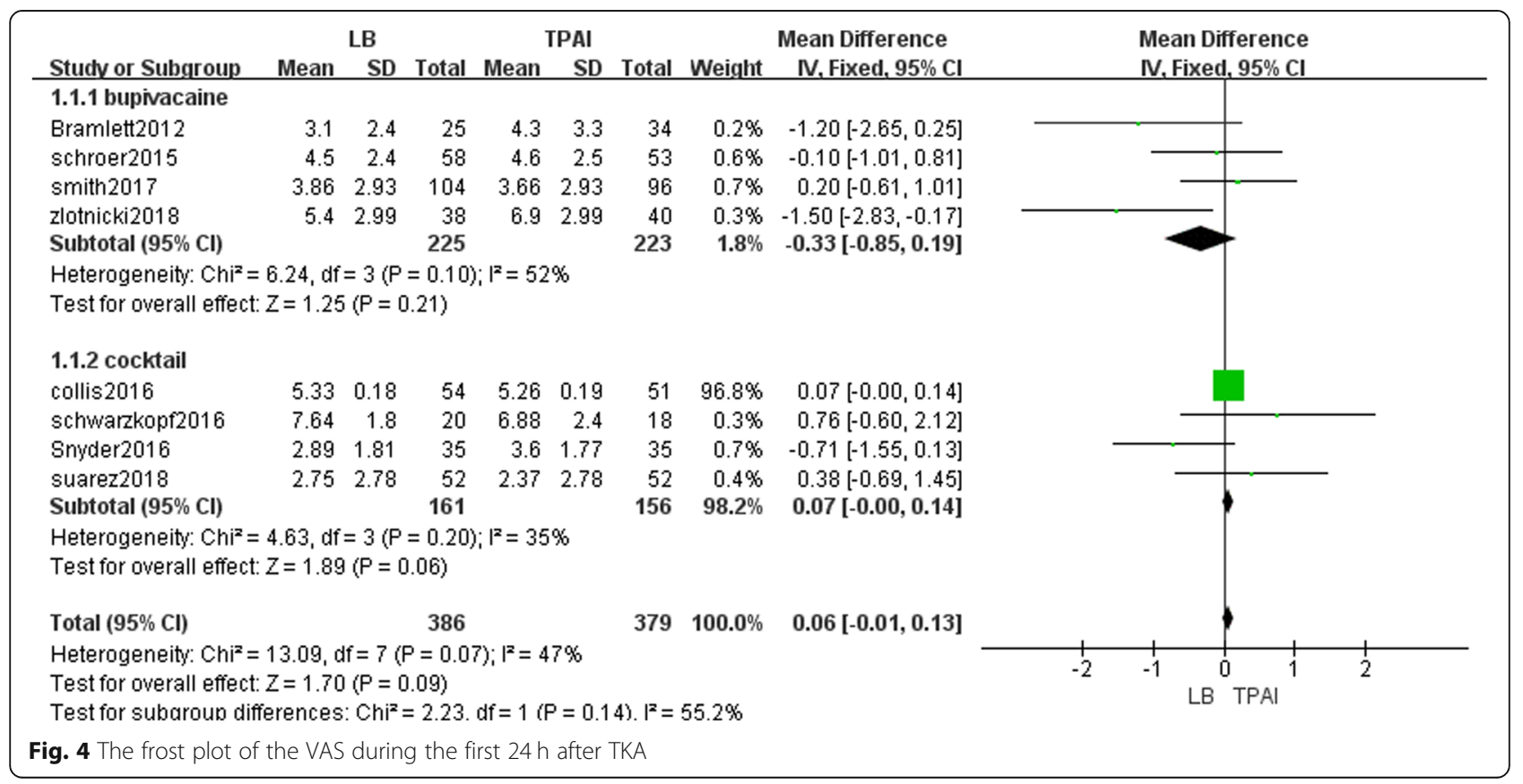




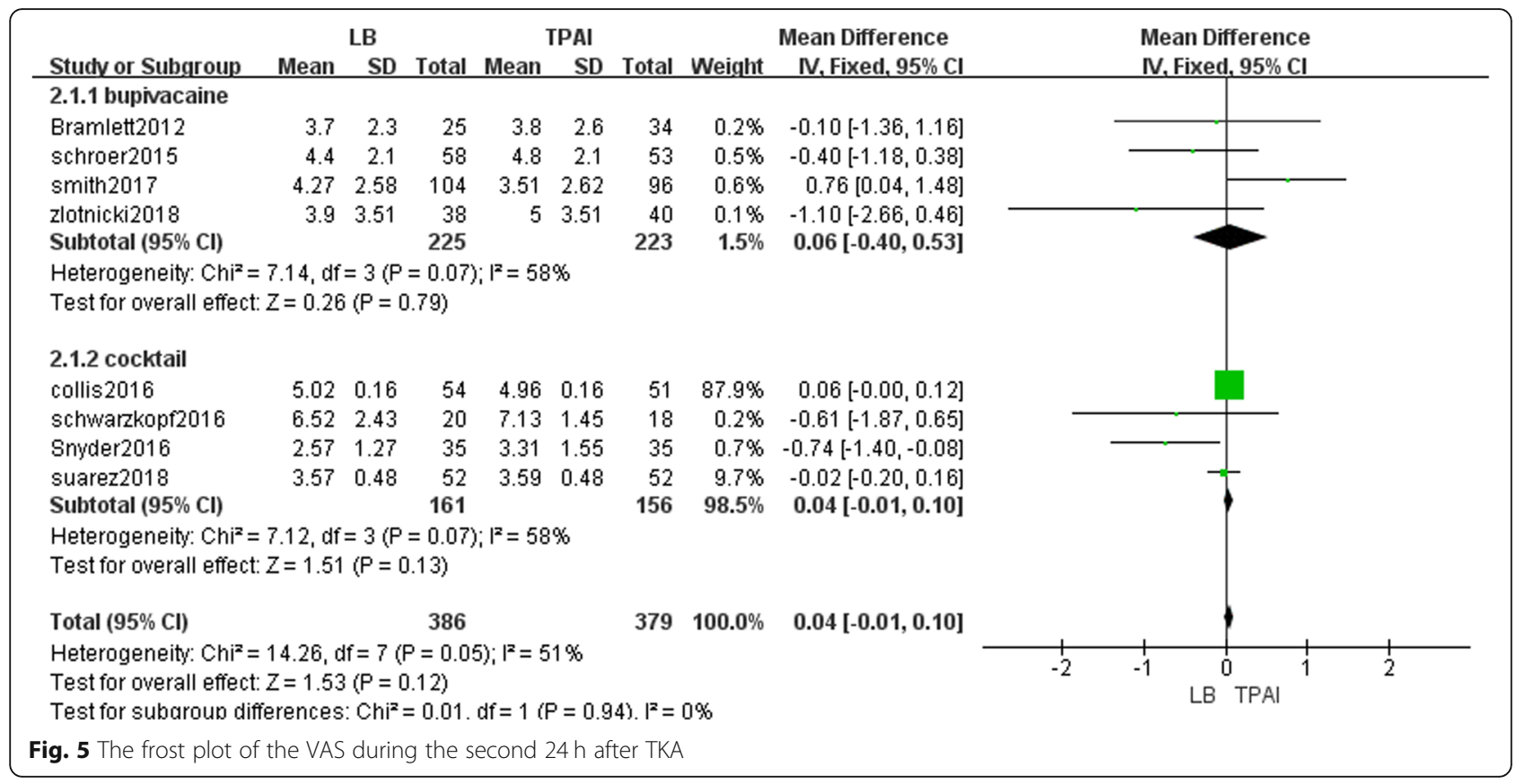

that the overall evidence quality of our meta-analysis was very moderate.

\section{Discussion}

\section{Summary of findings}

The purpose of our meta-analysis to explore the true efficacy of liposomal bupivacaine compared with traditional peri-articular injection following TKA. To our knowledge, this is the first meta-analysis that included more than 10 RCTs comparing LB and TPAI. The most significant finding of this study was that the liposomal bupivacaine did not make a difference regarding the visual analogue scale compared with traditional periarticular injection after total knee arthroplasty. In other words, liposomal bupivacaine did not decrease the visual analogue scale compared with traditional peri-articular injection, which is the primary outcome of our review.

The primary outcome in our study is the postoperative VAS, which is the most intuitive indicator reflecting the efficacy of postoperative pain control. The final result revealed that liposomal bupivacaine did not show superiority regarding VAS during every 24 -h period after TKA

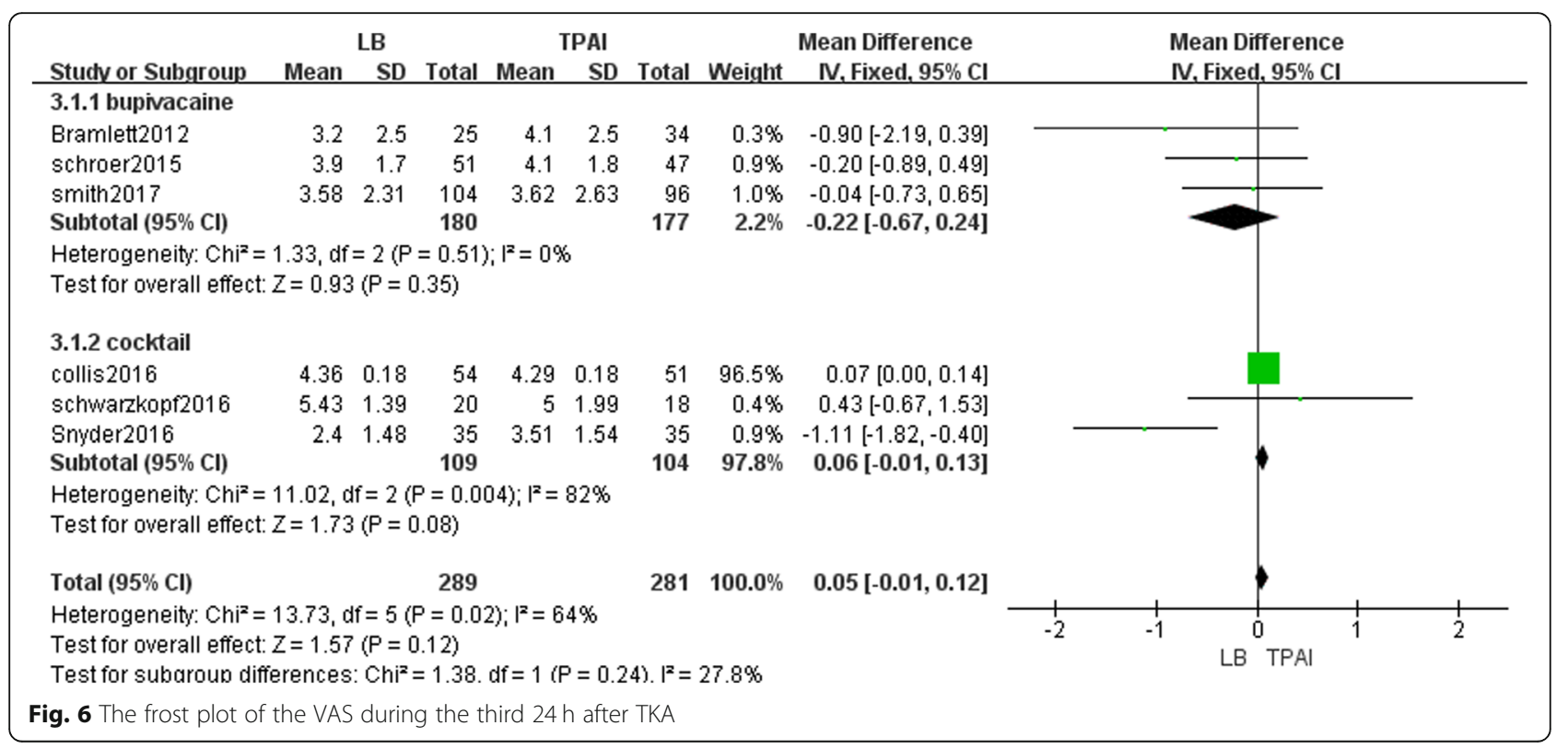




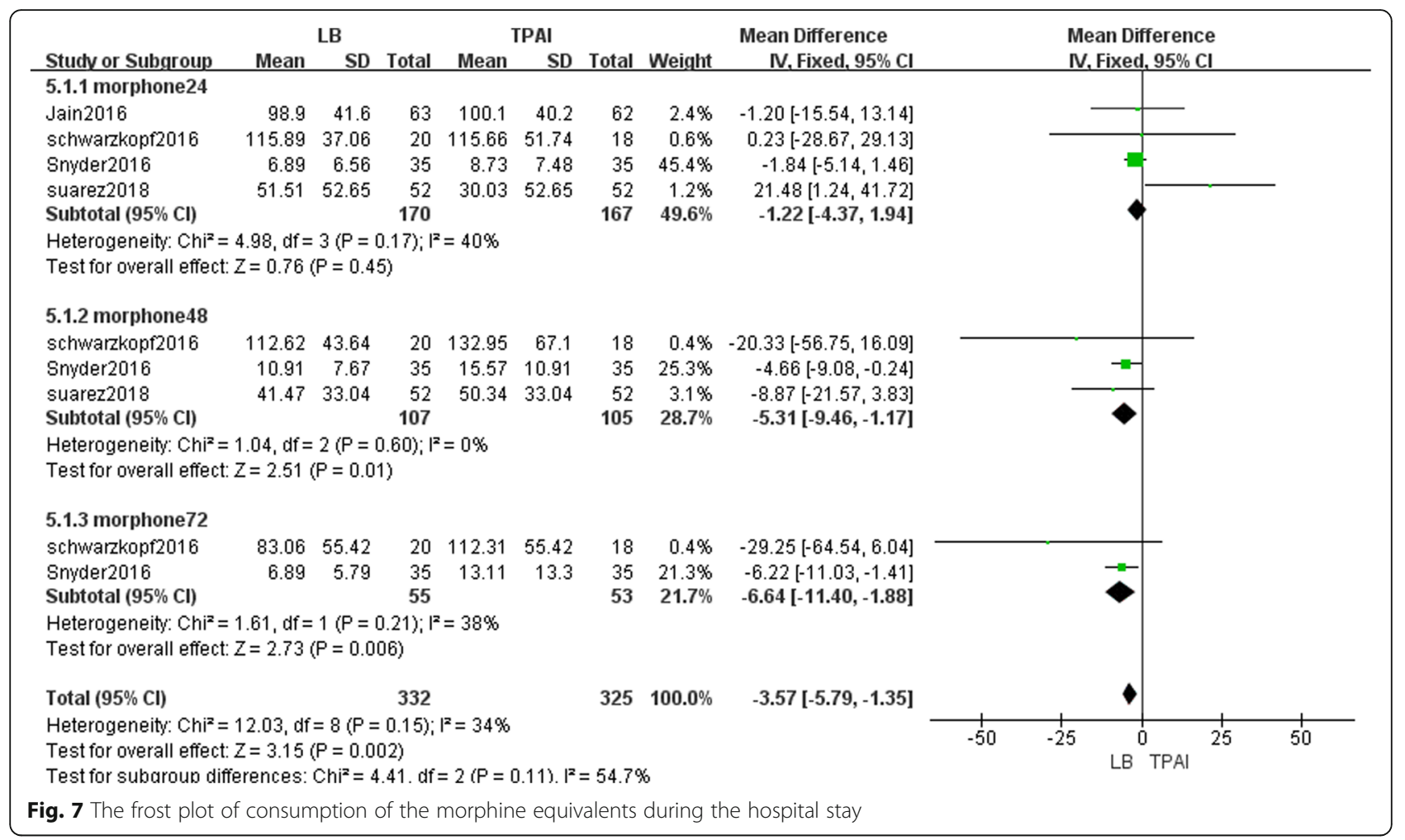

compared with TPAI, which is consistent with the result of a meta-analysis performed by Kuang et al. [10]. However, regarding the different amounts of additional topup analgesia, we think the VAS scores do not reflect LB or bupivacaine alone. Therefore, we analysed the amount of opioid use after TKA as a secondary outcome to further compare the true efficacy of liposomal bupivacaine with control group.

The secondary outcome includes three items. First, the patients in the liposomal bupivacaine group consumed significantly less morphine equivalents from 24 to $72 \mathrm{~h}$ postoperatively, which revealed that liposomal bupivacaine has better efficacy of pain control after $24 \mathrm{~h}$ compared with TPAI. Consistently, pharmacokinetic data of liposomal bupivacaine exhibited bimodal kinetics with rapid uptake observed during the first few hours and prolonged release through $96 \mathrm{~h}$ after administration. [29]. Dasta et al. [6] reported that liposomal bupivacaine administered with the PAI technique was associated with statistically significant and clinically meaningful lower VAS score at $72 \mathrm{~h}$ compared with the control group. In addition, a review [30] concluded that liposomal bupivacaine might have a promising future as an extended release bupivacaine formulation with an approximately 72 $\mathrm{h}$ duration. Second, consistent with the reduced consumption of morphine equivalents, patients in the LB group have a reduced incidence of nausea and vomiting (NAVO) after TKA. Third, the length of the hospital stay was not significantly different between the two groups, suggesting that the liposomal bupivacaine group did not

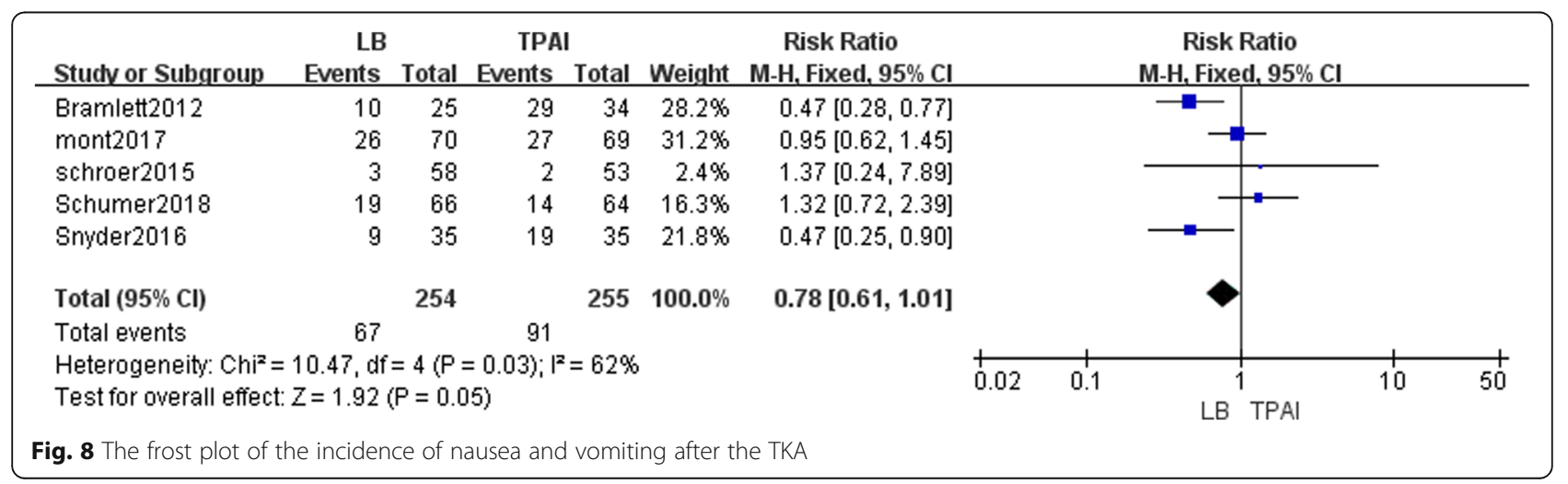




\begin{tabular}{|c|c|c|c|c|c|c|c|c|c|c|c|}
\hline \multirow[b]{2}{*}{ Study or Subgroup } & \multicolumn{3}{|c|}{ LB } & \multicolumn{2}{|c|}{ TPAI } & \multirow[b]{2}{*}{ Total } & \multirow{2}{*}{ Weight } & \multirow{2}{*}{$\begin{array}{l}\text { Mean Difference } \\
\text { IV. Fixed, 95\% Cl }\end{array}$} & \multirow{2}{*}{\multicolumn{3}{|c|}{$\begin{array}{l}\text { Mean Difference } \\
\text { IV, Fixed, } 95 \% \mathrm{Cl}\end{array}$}} \\
\hline & Mean & SD & Total & Mean & SD & & & & & & \\
\hline Collis2016 & 3.09 & 1.07 & 54 & 2.84 & 0.58 & 51 & $11.4 \%$ & $0.25[-0.08,0.58]$ & & & \\
\hline declaire2017 & 2.46 & 8.86 & 47 & 2.51 & 8.86 & 49 & $0.1 \%$ & $-0.05[-3.60,3.50]$ & & & \\
\hline Jain2016 & 1.4 & 0.9 & 63 & 1.2 & 0.4 & 62 & $20.5 \%$ & $0.20[-0.04,0.44]$ & & & \\
\hline schroer2015 & 2.9 & 0.4 & 58 & 3 & 0.5 & 53 & $42.3 \%$ & $-0.10[-0.27,0.07]$ & & $-a^{-}$ & \\
\hline Schumer2018 & 1.83 & 0.76 & 66 & 1.94 & 0.96 & 64 & $13.7 \%$ & $-0.11[-0.41,0.19]$ & & - & \\
\hline smith2017 & 2.6 & 3.05 & 104 & 2.5 & 3.05 & 96 & $1.7 \%$ & $0.10[-0.75,0.95]$ & & & \\
\hline suarez2018 & 2.02 & 0.89 & 52 & 1.79 & 0.89 & 52 & $10.4 \%$ & $0.23[-0.11,0.57]$ & & & \\
\hline Total $(95 \% \mathrm{Cl})$ & & & 444 & & & 427 & $100.0 \%$ & $0.04[-0.07,0.15]$ & & & \\
\hline $\begin{array}{l}\text { Heterogeneity: } \mathrm{Chi}^{2}= \\
\text { Test for overall effect }\end{array}$ & $\begin{array}{l}8.04, d f= \\
Z=0.67\end{array}$ & $\begin{array}{l}=6(P) \\
(P=0 .\end{array}$ & $\begin{array}{l}=0.23) \text {; } \\
.50)\end{array}$ & $i^{2}=25^{\circ}$ & & & & & -1 & -0.5 LB $^{0}{ }^{0.5}{ }^{0.5}$ & 1 \\
\hline
\end{tabular}

spend more time in functional recovery compared with the TPAI group.

\section{Strengths and limitations of the review}

The first strength of our review was that we only include randomized controlled trials into our review, which improved our review's level of evidence. In addition, more RCTs were included in our study than other reviews, which could help us acquire more believable results.

There are several limitations in our study. First, several actual analyses we report on only include a small sample of the 13 RCTs. For example, only 4 studies analysed opioid use, and 6 studies assessed VAS at varying time points. If more relevant, high-quality RCTs were included in our review, more useful information and results would be acquired. Second, the cocktail composition varied between studies and might influence the postoperative pain score and produce confounding bias. Third, given the limited number of included studies and data extracted, we did not compare the functional recovery between the two groups. However, the length of hospital stay was not significantly different in the two groups, revealing that the two groups spent a similar amount of time to reach the standard of leaving the hospital.

\section{Meaning of the study: implications for clinicians and researchers}

Postoperative pain management plays an important role in guaranteeing the final successful outcome of TKA. Inadequate pain control after TKA increases the consumption of rescue opioids, disrupts sleep, influences physical exercise, increases the length of hospital stay and total cost, and decrease the degree of satisfaction [4, 31]. Greater than 700, 000 TKA procedures performed annually in the USA [20],

Table 2 The GRADE evidence quality for each outcome

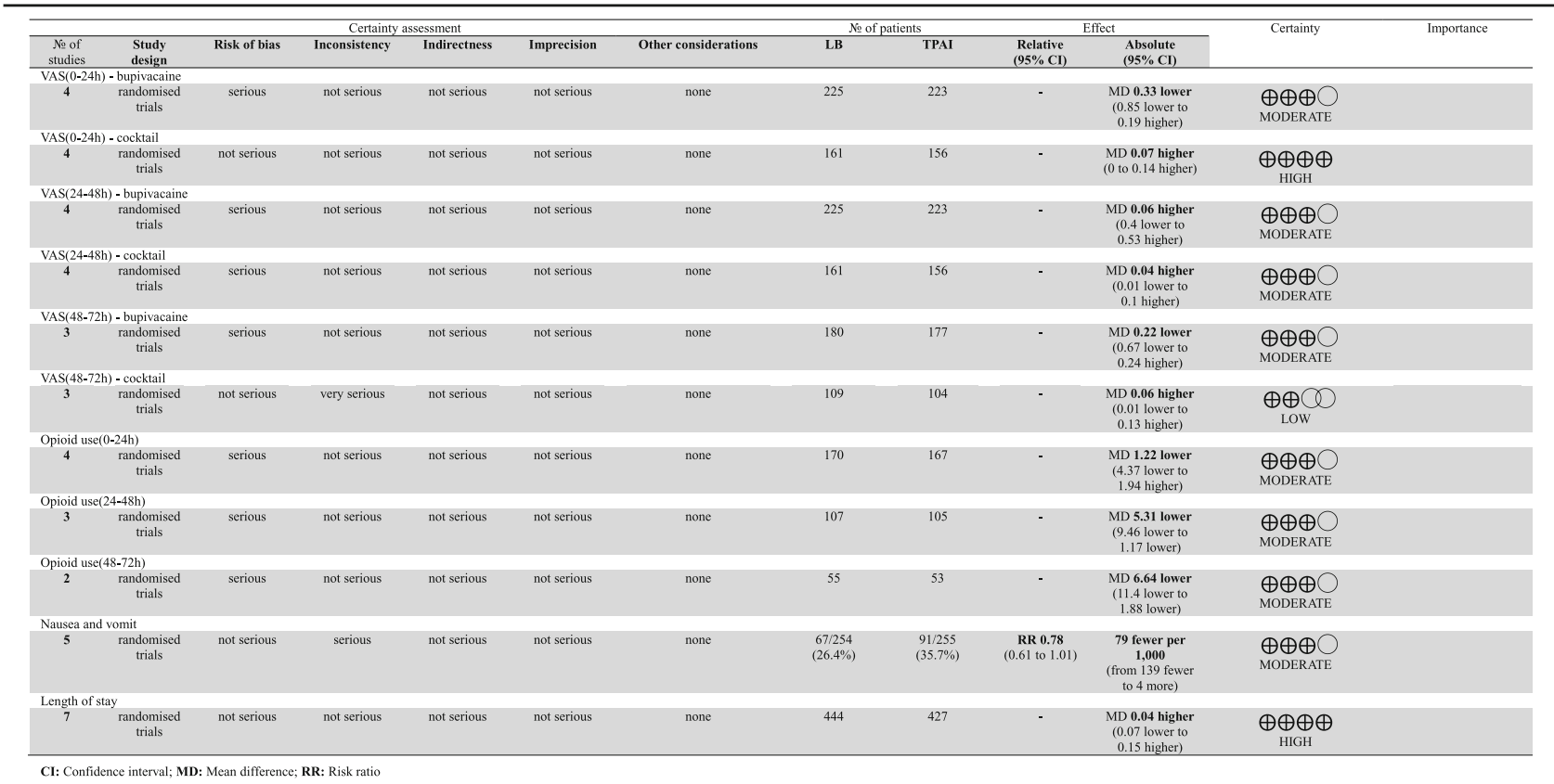


there is an urgent necessity to identify effective perioperative pain management that allows surgeons to be satisfied with the final outcome of TKA. Among the various types of measures, traditional peri-articular injection (TPAI) has been confirmed safe and effective in postoperative pain management after TKA [32-34]. Bupivacaine, ropivacaine, ketorolac, morphine, and epinephrine are usually used in combination as representative agents in a cocktail in TPAI.

Liposomal bupivacaine is an updated medication from bupivacaine, which is scraped from liposomes and injected into surgical site to alleviate postoperative pain. Since the drug was approved by the FDA in 2013, a series of clinical trials [35-37] and meta-analysis [9-11] have compared the efficacy of liposomal bupivacaine with traditional periarticular injection (TPAI) following total joint arthroplasty (TJA). Lonner et al. [35] concluded that it is an "effective mechanism to assist in early hospital discharge and rapid recovery after TJA." Barrington et al. [36] conduct a clinical trial with more than 1000 patients and demonstrated that LB showed superiority in lower pain scores and reduced length of hospital stay. Bagsby et al. [37] perform a retrospective cohort study and concluded that "liposomal bupivacaine PAI provided inferior pain control compared to the less expensive traditional PAI in a multi-modal pain control programme in patients undergoing TKA". Interestingly, the efficacy of liposomal bupivacaine was better in the meta-analysis performed by Wang et al. [9], similar in the meta-analysis conducted by Kuang et al. [10], and worse in the meta-analysis performed by Sun et al. [11]. Obviously, the comparison has not reached a unified recommendation.

\section{Future directions}

In terms of optimal efficacy and low cost, future studies should pay attention to the selection of the most effective drug composition for peri-articular injection for pain control after TKA. For example, Chai et al. [38] perform a meta-analysis and concluded that adding the corticosteroid to the multimodal cocktail is beneficial for pain control after TKA. Comparing the efficacy of liposomal bupivacaine with other analgesic methods is encouraged when three key points were considered. The first point is the consistency of the technique between the experiment and control group. We know liposomal bupivacaine was injected into the surgical site to reduce pain. Therefore, when we choose LB as the experimental group, use of the same peri-articular injection using different analgesic agents was ideal for the control group. This selection guarantees the consistency and decreases the confounding bias to yield credible outcomes in terms of statistics. The second point is that the time interval of 24 to $72 \mathrm{~h}$ postoperatively should receive more attention in the comparison. One advantage of liposomal bupivacaine is that it is effective to $72 \mathrm{~h}$ than general agents
[30]. Therefore, attention should be paid to the comparison from 24 to $72 \mathrm{~h}$ postoperatively when we compared LB with other analgesic methods. Moreover, most patients left the hospital before $72 \mathrm{~h}$ postoperatively; thus, future studies should record the number of patients compared after $24 \mathrm{~h}$ correctly [39]. The third point is that combined analgesia should be taken into account. A series of studies compared adductor canal block (ACB) combined with liposomal bupivacaine versus femoral nerve block (FNB) or ACB combined with local injection versus local injection alone after TKA [40-42]. It can be inferred that combined analgesia would have better efficacy than the single method, but the increased cost of pain control had to be considered.

\section{Conclusion}

Liposomal bupivacaine did not have an effect regarding the visual analogue scale compared with traditional periarticular injection after total knee arthroplasty. However, liposomal bupivacaine was preferred in terms of reduced consumption of morphine equivalents during $24-72 \mathrm{~h}$ postoperatively and reduced incidence of nausea and vomiting after total knee arthroplasty.

\section{Abbreviations \\ Cl: Confidence interval; LB: Liposomal bupivacaine; LOS: Length of hospital stay; MD: Mean differences; NAVO: Nausea and vomiting; RCT: Randomized controlled trials; RR: Relative risks; TKA: Total knee arthroplasty; \\ TPAI: Traditional peri-articular injection; VAS: Visual analogue score}

\section{Acknowledgements}

The authors would like to thank Zhen-ru Wu in Laboratory of Pathology, West China Hospital, Sichuan University for help with picture making and English polishing.

\section{Consent to publication}

Not applicable.

\section{Authors' contributions}

The following authors have designed the study (BS), gathered and analyzed the data (YL, YZ, JFZ), wrote the initial drafts (YL), and ensure the accuracy of the data and analysis (BS, MYL, WXW). All authors read and approved the final manuscript.

\section{Funding}

This study was not supported by any funding.

Availability of data and materials

All data and materials are contained within the manuscript.

Ethics approval and consent to participate

Ethical approval is not necessary because it is a comment on previously published articles and does not involve the handling of any personal patient data.

\section{Competing interests}

The authors declare that they have no competing interests.

Received: 22 March 2019 Accepted: 29 May 2019

Published online: 29 June 2019

\section{References}

1. Skou ST, Roos EM, Randomized LMBA. Controlled trial of Total knee replacement. N Engl J Med. 2016;374(7):692. https://doi.org/10.1056/ NEJMc1514794. 
2. Bedair H, Cha TD, Hansen VJ. Economic benefit to society at large of total knee arthroplasty in younger patients: a Markov analysis. J Bone Joint Surg Am. 2014;96(2):119-26. https://doi.org/10.2106/JBJS.L.01736.

3. Wheeler M, Oderda GM, Ashburn MA, Lipman AG. Adverse events associated with postoperative opioid analgesia: a systematic review. J Pain. 2002;3(3):159

4. Oderda GM, Said Q, Evans RS, Stoddard GJ, Lloyd J, Jackson K, Rublee D, Samore $\mathrm{MH}$. Opioid-related adverse drug events in surgical hospitalizations: impact on costs and length of stay. Ann Pharmacother. 2007;41(3):400-6.

5. Fu P, Wu Y, Wu H, Li X, Qian Q, Zhu Y. Efficacy of intra-articular cocktail analgesic injection in total knee arthroplasty - a randomized controlled trial. Knee. 2009;16(4):280-4. https://doi.org/10.1016/j.knee.2008.12.012.

6. Dasta J, Ramamoorthy S, Patou G, Sinatra R. Bupivacaine liposome injectable suspension compared with bupivacaine $\mathrm{HCl}$ for the reduction of opioid burden in the postsurgical setting. Curr Med Res Opin. 2012;28(10):1609-15. https://doi.org/10.1185/03007995.2012.721760.

7. Vyas KS, Rajendran S, Morrison SD, Shakir A, Mardini S, Lemaine V, Nahabedian MY, Baker SB, Rinker BD, Vasconez HC. Systematic review of liposomal Bupivacaine (Exparel) for postoperative analgesia. Plast Reconstr Surg. 2016 Oct;138(4):748e-56e. https://doi.org/10.1097/PRS. 0000000000002547.

8. Ellimoottil C, Vijan S, Flanigan RC. A primer on clinical trial design. Uro Oncol. 2015 Mar;33(3):116-21. https://doi.org/10.1016/j.urolonc.2014.12.014.

9. Wang $X$, Xiao L, Wang Z, Zhao G, Ma J. Comparison of peri-articular liposomal bupivacaine and standard bupivacaine for postsurgical analgesia in total knee arthroplasty: a systematic review and meta-analysis. Int J Surg. 2017 Mar;39:238-48. https://doi.org/10.1016/j.ijsu.2017.02.011.

10. Kuang MJ, Du Y, Ma JX, He W, Fu L, Ma XL. The efficacy of liposomal Bupivacaine using periarticular injection in Total knee arthroplasty: a systematic review and meta-analysis. J Arthroplast. 2017;32(4):1395-402. https://doi.org/10.1016/j.arth.

11. Sun $\mathrm{H}$, Huang Z, Zhang Z, Liao W. A meta-analysis comparing liposomal Bupivacaine and traditional periarticular injection for pain control after Total knee arthroplasty. J Knee Surg. 2019;32(3):251-8. https://doi.org/10.1055/s0038-1641141.

12. Schwarzkopf R, Drexler M, Ma MW, Schultz VM, Le KT, Rutenberg TF, Rinehart JB. Is there a benefit for liposomal Bupivacaine compared to a traditional periarticular injection in Total knee arthroplasty patients with a history of chronic opioid use? J Arthroplast. 2016:31(8):1702-5. https://doi. org/10.1016/j.arth.

13. Smith EB, Kazarian GS, Maltenfort MG, Lonner JH, Sharkey PF, Good RP. Periarticular liposomal Bupivacaine injection versus intra-articular Bupivacaine infusion catheter for analgesia after Total knee arthroplasty: a double-blinded, Randomized controlled trial. J Bone Joint Surg Am. 2017; 99(16):1337-44. https://doi.org/10.2106/JBJS.16.00571.

14. Wan X, Wang W, Liu J, Tong T. Estimating the sample mean and standard deviation from the sample size, median, range and/or interquartile range. BMC Med Res Methodol. 2014;14:135. https://doi. org/10.1186/1471-2288-14-135

15. Atkins D, Best D, Briss PA, Eccles M, Falck-Ytter Y, Flottorp S, Guyatt GH, Harbour RT, Haugh MC, Henry D, Hill S, Jaeschke R, Leng G, Liberati A, Magrini N, Mason J, Middleton P, Mrukowicz J, O'Connell D, Oxman AD, Phillips B, Schunemann HJ, Edejer T, Varonen H, Vist GE, Williams JJ, Zaza S. Grading quality of evidence and strength of recommendations. BMJ. 2004; 328:1490.

16. Atkins D, Eccles M, Flottorp S, Guyatt GH, Henry D, Hill S, Liberati A, O'Connell D, Oxman AD, Phillips B, Schunemann H, Edejer T, Vist GE, Williams JJ. Systems for grading the quality of evidence and the strength of recommendations l: critical appraisal of existing approaches the GRADE working group. BMC Health Serv Res. 2004:4:38.

17. Alijanipour P, Tan TL, Matthews CN, Viola JR, Purtill JJ, Rothman RH, Parvizi J, Austin MS. Periarticular injection of liposomal Bupivacaine offers no benefit over standard Bupivacaine in Total knee arthroplasty: a prospective, Randomized, controlled trial. J Arthroplast. 2017;32(2):628. https://doi.org/10. 1016/j.arth.2016.07.023.

18. Bramlett K, Onel E, Viscusi ER, Jones K. A randomized, double-blind, doseranging study comparing wound infiltration of DepoFoam bupivacaine, an extended-release liposomal bupivacaine, to bupivacaine $\mathrm{HCl}$ for postsurgical analgesia in total knee arthroplasty. Knee. 2012;19(5):530-6. https://doi.org/ 10.1016/j.knee.2011.12.004.

19. Collis PN, Hunter AM, Vaughn MD, Carreon LY, Huang J, Malkani AL. Periarticular injection after Total knee arthroplasty using liposomal Bupivacaine vs a modified Ranawat suspension: a prospective, Randomized study. J Arthroplast. 2016;31(3):633-6. https://doi.org/10.1016/j.arth.2015.09.025.

20. DeClaire $\mathrm{JH}$, Aiello PM, Warritay OK, Freeman DC. Effectiveness of Bupivacaine liposome injectable suspension for postoperative pain control in Total knee arthroplasty: a prospective, Randomized, double blind, controlled study. J Arthroplast. 2017;32(9, Supplement):S268. https://doi.org/ 10.1016/j.arth.2017.03.062.

21. Jain RK, Porat MD, Klingenstein GG, Reid JJ, Post RE, Schoifet SD. The AAHKS clinical research award: liposomal Bupivacaine and periarticular injection are not superior to single-shot intra-articular injection for pain control in Total knee arthroplasty. J Arthroplast. 2016;31(9 Suppl):22-5. https://doi.org/10. 1016/j.arth.2016.03.036.

22. Mont MA, Beaver WB, Dysart SH, Barrington JW, Del Gaizo DJ. Local infiltration analgesia with liposomal Bupivacaine improves pain scores and reduces opioid use after Total knee arthroplasty: results of a Randomized controlled trial. J Arthroplast. 2018;33(1):90-6. https://doi.org/10.1016/j.arth. 2017.07.024.

23. Schroer WC, Diesfeld PG, LeMarr AR, Morton DJ, Reedy ME. Does extendedrelease liposomal Bupivacaine better control pain than Bupivacaine after Total knee arthroplasty (TKA)? A prospective, Randomized clinical trial. J Arthroplast. 2015;30(9 Suppl):64-7. https://doi.org/10.1016/j.arth.2015.01.059.

24. Schumer G, Mann JW, Stover MD, Sloboda JF, Cdebaca CS, Woods GM. Liposomal Bupivacaine utilization in Total knee replacement does not decrease length of hospital stay. J Knee Surg. 2018. https://doi.org/10.1055/ s-0038-1673617.

25. Snyder MA, Scheuerman CM, Gregg JL, Ruhnke CJ, Eten K. Improving tota knee arthroplasty perioperative pain management using a periarticular injection with bupivacaine liposomal suspension. Arthroplast Today. 2016 Jan 11;2(1):37-42. https://doi.org/10.1016/j.artd.2015.05.005.

26. Suarez JC, Al-Mansoori AA, Kanwar S, Semien GA, Villa JM, McNamara CA, Patel PD. Effectiveness of novel adjuncts in pain management following Total knee arthroplasty: a Randomized clinical trial. J Arthroplast. 2018 Jul; 33(7S):S136-41. https://doi.org/10.1016/j.arth.2018.02.088.

27. Zlotnicki JP, Hamlin BR, Plakseychuk AY, Levison TJ, Rothenberger SD, Urish $\mathrm{KL}$. Liposomal Bupivacaine vs plain Bupivacaine in periarticular injection for control of pain and early motion in Total knee arthroplasty: a Randomized, prospective study. J Arthroplast. 2018 Aug;33(8):2460-4. https://doi.org/10. 1016/j.arth.2018.03.014

28. Saltaji H, Ospina MB, Armijo-Olivo S, Agarwal S, Cummings GG, Amin M, Flores-Mir C. Evaluation of risk of bias assessment of trials in systematic reviews of oral health interventions, 1991-2014: a methodology study. J Am Dent Assoc. 2016;09:147(9).

29. Hu D, Onel E, Singla N, Kramer WG, Hadzic A. Pharmacokinetic profile of liposome bupivacaine injection following a single administration at the surgical site. Clin Drug Investig. 2013 Feb;33(2).

30. Malik O, Kaye AD, Kaye A, Belani K, Urman RD. Emerging roles of liposomal bupivacaine in anesthesia practice. J Anaesthesiol Clin Pharmacol. 2017; 33(2):151-6. https://doi.org/10.4103/joacp. JOACP_375_15

31. Dalury DF, Lieberman JR, Macdonald SJ. Current and innovative pain management techniques in total knee arthroplasty. Instr Course Lect. 2012; 61:383-8.

32. Fu P, Wu Y, Wu H, Li X, Qian Q, Zhu Y. Efficacy of intra-articular cocktail analgesic injection in total knee arthroplasty - a randomized controlled trial. Knee. 2009;16(4):280. https://doi.org/10.1016/j.knee.2008.12.012.

33. Mullaji A, Kanna R, Shetty GM, Chavda V, Singh DP. Efficacy of periarticular injection of bupivacaine, fentanyl, and methylprednisolone in total knee arthroplasty. a prospective, randomized trial J Arthroplasty. 2010;25(6):851. https://doi.org/10.1016/j.arth.2009.09.007.

34. Joo JH, Park JW, Kim JS, Kim YH. Is intra-articular multimodal drug injection effective in pain management after total knee arthroplasty? A randomized, double-blinded, prospective study J Arthroplasty. 2011;26(7):1095. https:// doi.org/10.1016/j.arth.2011.03.052.

35. Role of liposomal bupivacaine in pain management after total joint arthroplasty. A Lonner J J. J Surg Orthop Adv. 2014;23(1):37.

36. Barrington JW, Olugbode O, Lovald S, Ong K, Watson H, Bupivacaine ERHJL. A comparative study of more than 1000 Total joint arthroplasty cases. Orthop Clin North Am. 2015;46(4):469-77. https://doi.org/10.1016/j.ocl.2015.06.003.

37. Bagsby DT, Ireland PH, Meneghini RM. Liposomal bupivacaine versus traditional periarticular injection for pain control after total knee arthroplasty. J Arthroplast. 2014;29(8):1687-90. https://doi.org/10.1016/j.arth. 2014.03.034. 
38. Chai X, Liu H, You C, Wang C. Efficacy of additional corticosteroid in a multimodal cocktail for postoperative analgesia following Total knee arthroplasty: a meta-analysis of Randomized controlled trials. Pain Pract. 2019 Mar;19(3):316-27. https:/doi.org/10.1111/papr.12740.

39. El Bitar YF, Illingworth KD, Scaife SL, Horberg JV, Saleh KJ. Hospital length of stay following primary Total knee arthroplasty: data from the Nationwide inpatient sample database. J Arthroplast. 2015 Oct;30(10):1710-5. https://doi. org/10.1016/j.arth.2015.05.003.

40. Sandhu S, Zadzilka JD, Nageeb E, Siqueira M, Klika AK, Molloy RM, Higuera CA. A comparison of pain management protocols following Total knee arthroplasty: femoral nerve block versus periarticular injection of liposomal Bupivacaine with an Adductor Canal block. Surg Technol Int. 2018; 34. pii: sti34/1075.

41. Phillips J, Doshi A. Effects of liposomal Bupivacaine with Adductor Canal block on pain and functional outcomes in patients undergoing Total knee arthroplasty. Ann Pharmacother. 2016 Sep;50(9):706-11. https://doi.org/10. 1177/1060028016653607.

42. Li Y, Li A, Zhang Y. The efficacy of combined adductor canal block with local infiltration analgesia for pain control after total knee arthroplasty: a meta-analysis. Medicine (Baltimore). 2018 Dec;97(49):e13326. https://doi.org/ 10.1097/MD.0000000000013326.

\section{Publisher's Note}

Springer Nature remains neutral with regard to jurisdictional claims in published maps and institutional affiliations.

Ready to submit your research? Choose BMC and benefit from:

- fast, convenient online submission

- thorough peer review by experienced researchers in your field

- rapid publication on acceptance

- support for research data, including large and complex data types

- gold Open Access which fosters wider collaboration and increased citations

- maximum visibility for your research: over $100 \mathrm{M}$ website views per year

At $\mathrm{BMC}$, research is always in progress.

Learn more biomedcentral.com/submissions 